\title{
Stachytarpheta cayennensis Aqueous Extract, a New Bioreactor towards Silver Nanoparticles for Biomedical Applications
}

\author{
Francois Eya'ane Meva1,2* ${ }^{1}$, Joel Olivier Avom Mbeng1, Cecile Okalla Ebongue ${ }^{1,3}$, \\ Carsten Schlüsener ${ }^{2}$, Ülkü Kökçam-Demir ${ }^{2}$, Agnes Antoinette Ntoumba ${ }^{4}$, \\ Phillipe Belle Ebanda Kedi ${ }^{4}$, Etienne Elanga ${ }^{1}$, Evrard-Rudy Njike Loudang1, \\ Moise Henri Julien Nko'o ${ }^{1}$, Edmond Tchoumbi ${ }^{1}$, Vandi Deli ${ }^{1}$, Christian Chick Nanga ${ }^{1}$, \\ Emmanuel Albert Mpondo Mpondo', Christoph Janiak ${ }^{2}$ \\ ${ }^{1}$ Department of Pharmaceutical Sciences, Faculty of Medicine and Pharmaceutical Sciences, University of Douala, \\ Douala, Cameroon \\ ${ }^{2}$ Institute for Inorganic Chemistry and Structural Chemistry, Heinrich-Heine-University Düsseldorf, \\ Düsseldorf, Germany \\ ${ }^{3}$ Clinical Biology Laboratory, General Hospital of Douala, Douala, Cameroon \\ ${ }^{4}$ Department of Animal Biology and Physiology, Faculty of Science, University of Douala, Douala, Cameroon \\ Email: *mevae@daad-alumni.de
}

How to cite this paper: Meva, F.E., Mbeng, J.O.A., Ebongue, C.O., Schlüsener, C., Kökçam-Demir, Ü., Ntoumba, A.A., Kedi, P.B.E., Elanga, E., Loudang, E.-R.N., Nko'o, M.H.J., Tchoumbi, E., Deli, V., Nanga, C.C., Mpondo, E.A.M. and Janiak, C. (2019) Stachytarpheta cayennensis Aqueous Extract, a New Bioreactor towards Silver Nanoparticles for Biomedical Applications. Journal of Biomaterials and Nanobiotechnology, 10, 102-119.

https://doi.org/10.4236/jbnb.2019.102006

Received: February 6, 2019

Accepted: April 20, 2019

Published: April 23, 2019

Copyright $\odot 2019$ by author(s) and Scientific Research Publishing Inc. This work is licensed under the Creative Commons Attribution International License (CC BY 4.0).

http://creativecommons.org/licenses/by/4.0/ (c) (i) Open Access

\begin{abstract}
This study reports the preparation and characterization of silver nanoparticles synthesized by the mediation of the plant weed Stachytarpheta cayennensis through solution method. Ultraviolet visible spectroscopy (UV-Vis) determines the presence of nanoparticles in the solution. Infrared spectroscopy (IR) proves organic molecules at the particles interface. Powder X-ray diffraction (PXRD) provides phase composition and crystallinity. Shape was showed by scanning electron microscopy (SEM), and energy dispersive X-ray spectroscopy (EDX) demonstrated the elemental mapping of the silver nanoparticles. Hydrogen peroxide scavenging and phosphomolybdenum antioxidant assays, egg albumin denaturation anti-inflammation study, and the formation mechanism complete the study. The particles have been found composed of pure silver $\mathrm{Ag}$ and silver chloride $\mathrm{AgCl}$ nanocrystallites. The average crystallite sizes were found to be $13 \mathrm{~nm}$ and $20 \mathrm{~nm}$ for $\mathrm{Ag}$ and $\mathrm{AgCl}$ respectively. A Rietveld refinement based XRD pattern data followed by Williamson-Hall plot allows a size and strain analysis. Based on SEM, spherical agglomerates materials were formed and EDX proved the presence of $\mathrm{Cl}^{-}$ions. The reaction formation mechanism of $\mathrm{Ag}$ and $\mathrm{AgCl}$ is proposed to be simultaneous and competitive. The silver nanoparticles moderately inhibit the denaturation of egg albumin and exhibit antioxidant action; hence, the nano-
\end{abstract}


particles could be considered as a potential source for biomedical applications.

\section{Keywords}

Silver Nanoparticles, Stachytarpheta cayennensis, Size and Strain, Anti-Oxidant, Anti-Inflammation

\section{Introduction}

One of the most direct effects of reducing the size of materials to the nanometer range is appearance of quantization effects due to the confinement of the movement of electrons, which leads to discrete energy levels depending on the size of the structure. Control over dimensions as well as composition of structures makes it possible to tailor material properties to specific applications which are influenced by quantum confinement effect (QCE) [1]. Hence, quantum confinement (QC) in semiconductors results from the geometric confinement of electrons, holes or excitons (electron hole bound pair). When an electron-hole pair is squeezed below the dimensions approaching excitons Bohr radius, quantum confinement effects become prominent in the structure and the effective band gap increases. The smaller the nanostructure, the larger the effective band gap and the greater the energy of the optical emission, which changes the optical and the electronic properties, when the sample size is sufficiently smaller than 10 $\mathrm{nm}$ [2]. Nanoparticles are considered to be the future building blocks of advanced materials and devices that can satisfy several promises of nanotechnology [3]. Nanoparticles with particular shapes and dimensions have been obtained by various techniques including physicochemical and biological routes. Material scientists are developing research towards novel materials with better properties, more functionalities and lower cost than the existing ones. In this light, methods are employed to improve the nano-entity performance to gain better control over particle size, distribution and morphology [4]. The physical and chemical processes of nanoparticles production are typically expensive and require hazardous chemicals while the "green synthesis" approach is environmentally benign and cost-effective. Plants represent the most explored group of living organisms for the green synthesis of nanoparticles [5]. The use of natural products can also lead to capping groups that are biocompatible, circumventing the need for ligand exchange prior to biological applications [6]. However, greener, more sustainable or biogenic methods do not guarantee the fabrication of nanomaterials with improved or even identical properties to those produced by traditional methods [6]. One of the critical goals is the satisfactory reproducibility of synthesized materials.

Weeds, the unwanted plants in the agriculture fields can be used in the synthesis of nanoparticles. Silver nanoforms have been described with plant weeds 
such as Parthenium [7], Ipomoea aquatica, Enhydra fluctuans and Ludwigia adscendens [8].

Stachytarpheta cayennensis (L. C. Rich) Vahl is a ligneous weed $0.5-1 \mathrm{~m}$ high. The plant leaves are used in folk medicine in infusion as a stomachic and febrifuge to treat chronic liver diseases, flues, cough and arthritis and also as a diuretic and sudorific [9]. The leave extracts have been reported for hypoglycemic, antimicrobial and antispasmodic activity [10] [11]. Phytochemical screening revealed the presence of saponins, carbohydrates, flavonoids and terpenoids [11].

In the current study, we report the first use of Stachytarpheta cayennensis plant extract for silver nanoparticle synthesis. In-vitro antioxidant and anti-inflammatory experiments are conducted considering the potential pharmacological use of the nanoparticles.

\section{Material and Methods}

\subsection{Plant Material and Extract Preparation}

Whole plants of Stachytarpheta cayennensis (L. C. Rich) Sehau (Figure 1) were procured from the University of Douala, Cameroon. Plant identification was confirmed at the National Herbarium of Cameroon under number specimen 21136/SRF Cam. The organic material was surface cleaned with running tap water followed by de-ionized water to remove all the dust and unwanted visible particles. Aqueous plant extracts were prepared by boiling $10 \mathrm{~g}$ of organic material in $200 \mathrm{~mL}$ of de-ionized water for $5 \mathrm{~min}$ at $80^{\circ} \mathrm{C}$. The extract was filtered through Whatman No. 1 filter paper to remove particulate matter. The obtained clear solution was then stored at $4^{\circ} \mathrm{C}$ for further use, being usable for one week due to the gradual loss of plant extract viability for prolonged storage [12].

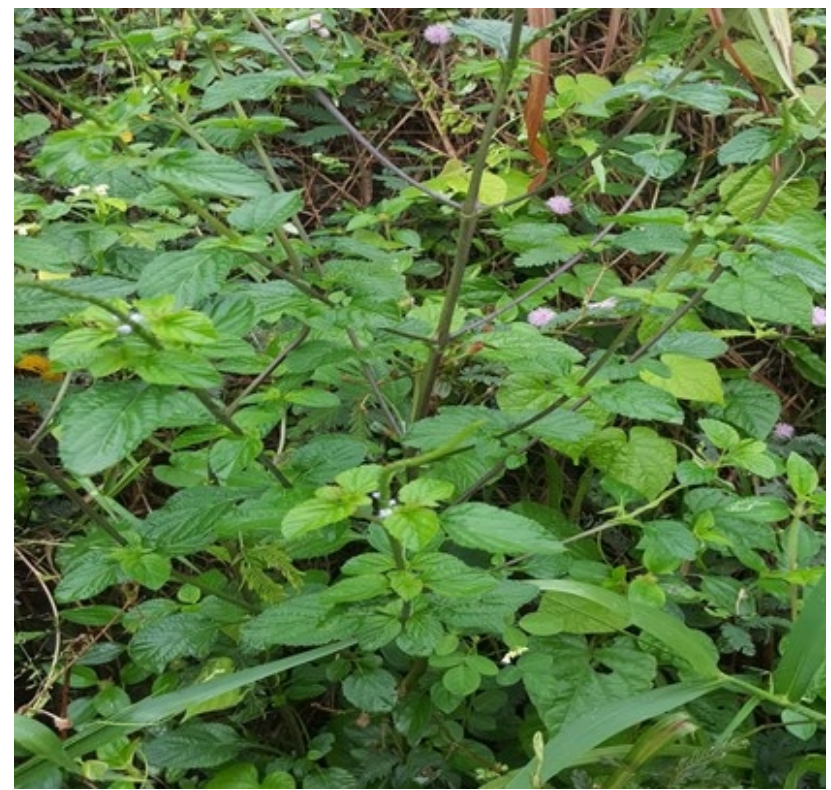

Figure 1. Stachytarpheta cayennensis in natural media. 


\subsection{Synthesis of Silver Nanoparticles}

Silver nitrate $\left(\mathrm{AgNO}_{3}\right)$ was obtained from Sigma-Aldrich chemicals Germany. De-ionized water was used throughout the reactions. All glass wares were washed with dilute nitric acid $\left(\mathrm{HNO}_{3}\right)$ and de-ionized water, and then dried in hot air oven. A solution of $\mathrm{AgNO}_{3} 10^{-3} \mathrm{~mol} / \mathrm{L}$ was prepared in de-ionized water. As a standard procedure, $10 \mathrm{~mL}$ of organic material extract was added to $50 \mathrm{~mL}$ of $10^{-3} \mathrm{~mol} / \mathrm{L}$ aqueous $\mathrm{AgNO}_{3}$ solution, hand shaken during $1 \mathrm{~min}$, and incubated at room temperature in the dark to minimize the photoactivation of silver nitrate. The reactions were made under static conditions.

\subsection{Ultraviolet-Visible Spectroscopy (UV-Vis)}

The reaction was monitored by ultraviolet visible spectroscopy of the reaction suspension $(2.5 \mathrm{~mL})$ using an UV-visible Uviline 9100 spectrophotometer operating at $1 \mathrm{~nm}$ resolution with optical length of $10 \mathrm{~mm}$. Concentrations were determined after 24 hours of incubation by centrifugation at $6000 \mathrm{rpm}$ during 1 hour. UV-Vis analysis of the reaction mixture was observed for a period of $300 \mathrm{~s}$.

\subsection{Infrared Spectroscopy (IR)}

The Fourier Transform Infrared spectrum (FTIR) of copper nanoparticles was recorded with a Nicolet iS5 FT-IR Spectrometer. The sample was prepared at $0.25 \mathrm{~mm}$ thickness as $\mathrm{KBr}$ pellets. The spectrum was measured between 400 and $4000 \mathrm{~cm}^{-1}$ at a resolution of $0.4 \mathrm{~cm}^{-1}$.

\subsection{Powder X-Ray Diffraction (PXRD)}

Powder X-ray diffraction measurements were carried out at ambient temperature using a BRUKER D2 Phaser diffractometer (Cu K-Alpha [A] 1.54182, 35 $\mathrm{kV}$ ) by preparing a film of the silver-organic nano-powder on the flat, low background silicon sample holder. The peaks and phase were identified using the profile matching routine of MATCH Version 3 program [13] and the Rietveld refinement was carried out using the Fullprof 2000 software package [14].

\subsection{Scanning Electron Microscopy (SEM) and Energy Dispersive X-Ray Spectroscopy (EDX)}

Scanning electron microscopy images and energy dispersive X-ray spectrometric measurements where done on a Jeol scanning electron microscope JSM-6510 with a tungsten cathode and an EDX unit. The samples were coated with Au for $20 \mathrm{~s}$ at $30 \mathrm{~mA}$ by using a Jeol JFC-1200 sputter coater (JSM-6510). Microscopy provides detailed characterization of the distribution and morphology of the nanoparticles and the presence of nano-silver elements was confirmed by EDX at $20 \mathrm{keV}$.

\subsection{Antioxidant Activity}

\subsubsection{Hydrogen Peroxide Scavenging Assay}

The experiment was carried out using the modified methods of Bhakya et al. 
(2016), by reacting $4 \mathrm{~mL}$ of graded concentrations of AgNPs $(50 \mu \mathrm{g} / \mathrm{mL}$ to 3 $\mu \mathrm{g} / \mathrm{mL}$ ) with $0.6 \mathrm{ml}$ of $40 \mathrm{mM} \mathrm{H} \mathrm{H}_{2}$ prepared in phosphate buffer ( $\mathrm{pH} 7.4$ ) at room temperature $\left(30^{\circ} \mathrm{C} \pm 2^{\circ} \mathrm{C}\right)$ for $20 \mathrm{~min}$. [15]. While distilled water was used as blank, the $\mathrm{H}_{2} \mathrm{O}_{2}$ solution was used as the control, and absorbance readings were made at $610 \mathrm{~nm}$. The percentage antioxidant activity was calculated by formula 1. Ascorbic acid was used as positive reference standard.

$$
\text { Percentage antioxidant activity }=\left[\frac{\left(A_{\text {control }}-A_{\text {sample }}\right)}{A_{\text {control }}}\right] \times 100
$$

\subsubsection{Phosphomolybdenum Assay}

The antioxidant capacity was evaluated by the phosphomolybdenum method [16], with modifications. The phosphomolybdate reagent solution was prepared by adding $1 \mathrm{~mL}$ of each $0.6 \mathrm{M}$ sulphuric acid, $28 \mathrm{mmol} / \mathrm{L}$ sodium phosphate and $4 \mathrm{mmol} / \mathrm{L}$ ammonium molybdate to $20 \mathrm{~mL}$ of distilled water and the volume brought to $50 \mathrm{~mL}$ by adding distilled water. Different concentrations of nanoparticles ranging from $50 \mu \mathrm{g} / \mathrm{mL}$ to $3 \mu \mathrm{g} / \mathrm{mL}$ were added to each test tube individually containing $3 \mathrm{~mL}$ of distilled water and $1 \mathrm{~mL}$ of molybdate reagent solution. These tubes were kept incubated at $95^{\circ} \mathrm{C}$ for $90 \mathrm{~min}$. After incubation these tubes were normalized to room temperature for 20 - $30 \mathrm{~min}$ and the absorbance of the reaction mixture was measured at $695 \mathrm{~nm}$. Ascorbic acid was used as positive reference standard.

\subsection{Anti-Inflammatory Activity}

Egg albumin denaturation assay: The reaction mixture $(5 \mathrm{~mL})$ consisted of 0.2 $\mathrm{mL}$ of egg albumin (from fresh hen's egg), $2.8 \mathrm{~mL}$ of phosphate buffered saline (PBS, pH 6.4) and $2 \mathrm{~mL}$ of varying concentrations of extract so that final concentrations become $50,25,12.5,6.25,3.125 \mu \mathrm{g} / \mathrm{mL}$. Similar volume of double-distilled water served as control. Then the mixtures were incubated at $\left(37^{\circ} \mathrm{C} \pm 2^{\circ} \mathrm{C}\right)$ in an incubator for $15 \mathrm{~min}$ and then heated at $70^{\circ} \mathrm{C}$ for $5 \mathrm{~min}$. After cooling, their absorbance was measured at $660 \mathrm{~nm}$ by using vehicle as blank [17] [18]. Ibuprofen at the final concentration of $50,25,12.5,6.25,3.125 \mu \mathrm{g} / \mathrm{mL}$, was used as reference drug and treated similarly for determination of absorbance. The percentage inhibition of protein denaturation was calculated by using the formula 1 .

\subsection{Statistical Analysis}

The experiments were carried out in triplicate and the results are given as mean \pm standard deviation (SD). A sample analysis test was used for the comparison between the means of samples and standard. Values with $\mathrm{p}<0.05$ are considered significant. Correlation analysis was carried out for the activities using Excel-2016.

\subsection{Ethical Considerations}

All experiments were carried out according to the approved protocol by the In- 
stitutional Ethical Committee of the University of Douala (Protocol approval numbers CEI-UDo/895/16/2017/T and CEI-UDo/1309/03/2018/T).

\section{Results}

\subsection{UV-Vis Spectroscopy}

The absorption spectra of the synthesized silver nanoparticles are recorded against water in order to monitor the formation and stability of silver nanoparticles. The visual observation of the colour change of the mixture solution plant extract and silver ion is the preliminary evaluation. Colours of silver nitrate, Stachytarpheta cayennensis leaf extract and silver nanoparticles solution is shown in Figure 2. The sharp surface plasmon resonance absorbance band has been obtained at $449 \mathrm{~nm}$ (Figure 3).

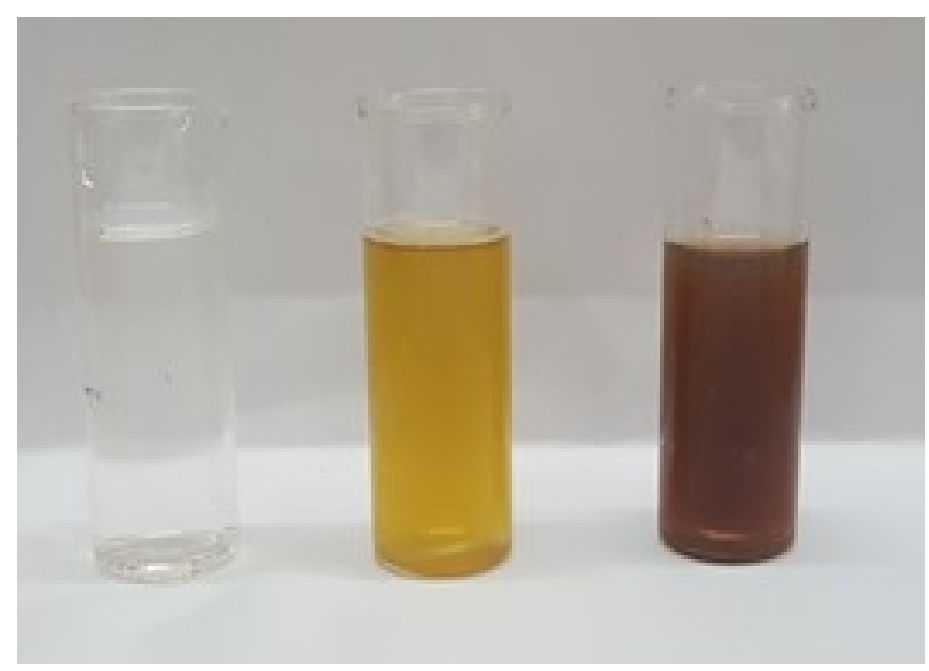

Figure 2. Silver nitrate, Stachytarpheta cayennensis leaf extract, Ag nanoparticles solution.

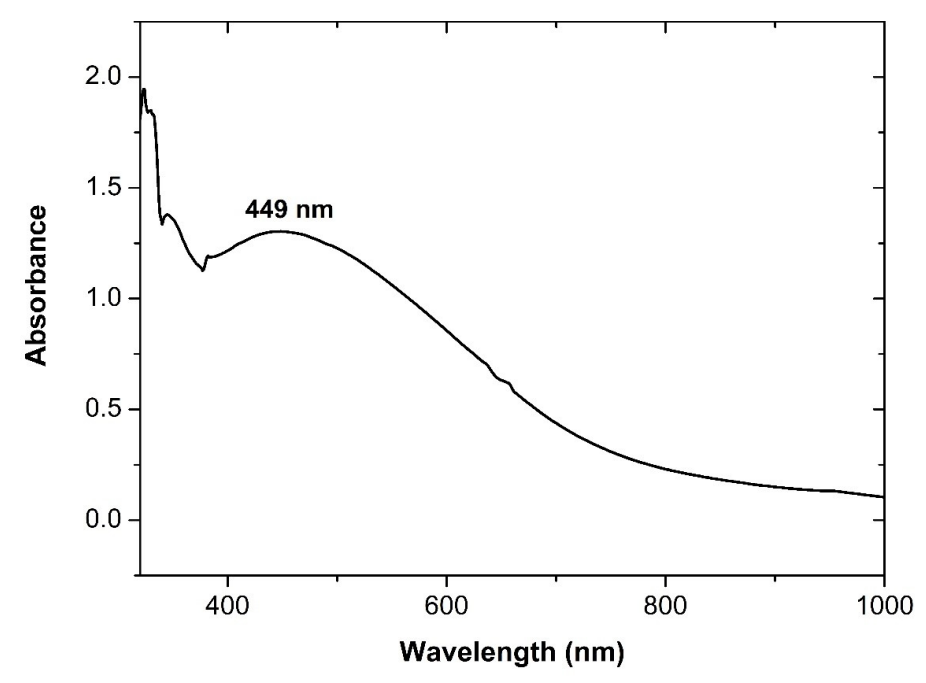

Figure 3. UV-Vis spectra of silver nanoparticles formed from Stachytarpheta cayennensis leaf extract. 


\subsection{PXRD Analysis}

PXRD is one of the most important characterization techniques to reveal the structural properties of NPs. It gives enough information about the crystallinity and phase of the nanoparticles. The PXRD pattern of the prepared silver nanoparticles mediated Stachytarpheta cayennensisis shown in Figure 4. The pattern is compatible with the cubic phase of $\mathrm{Ag}$ with diffraction points at $2 \theta$ values of $38^{\circ}, 44.1^{\circ}, 64.4^{\circ}$ and $77.3^{\circ}$ and can be indexed to the (111), (200), (220), and (311) planes of the face centered cubic (fcc) structure (ICCD file: 65-2871). The XRD pattern also showed the presence of the cubic phase of $\mathrm{AgCl}$ at $2 \theta$ values of $27.7^{\circ}, 32.1^{\circ}, 46.1^{\circ}, 54.7^{\circ}$ and $57.4^{\circ}$, corresponding to the (111), (200), (220), (311) and (222) planes, respectively (JCPDS file: 31-1238). The average crystallite size of the synthesized nanoparticles is determined using the Scherrer equation:

$$
D v=\frac{K \lambda}{\beta}+\cos \theta
$$

where $D v$ is the average crystalline size; $K$ is a dimensionless shape factor, with a value close to unity (0.9); $\lambda$ is the wavelength of $\mathrm{Cu} \mathrm{K} \alpha ; \beta$ is the full width at half-maximum of the diffraction peaks, and $\theta$ is Bragg's angle.

The Williamson-Hall analysis relies on the principle that the approximate formula for the size broadening and the strain broadening vary quite differently with respect to the Bragg angle [19]. The crystallite size and strain can be obtained from the intercept at y-axis and the slope of line, respectively.

$$
\beta \cos \theta=\frac{C \lambda}{t}+4 \varepsilon \sin \theta
$$

where $\beta$ is FWHM in radian, $t$ is the grain size in $\mathrm{nm}, \mathcal{\varepsilon}$ is the strain, $\lambda$ is the $\mathrm{X}$-ray wavelength in nanometers, and $C$ is a correction factor taken as 0.94 [20].

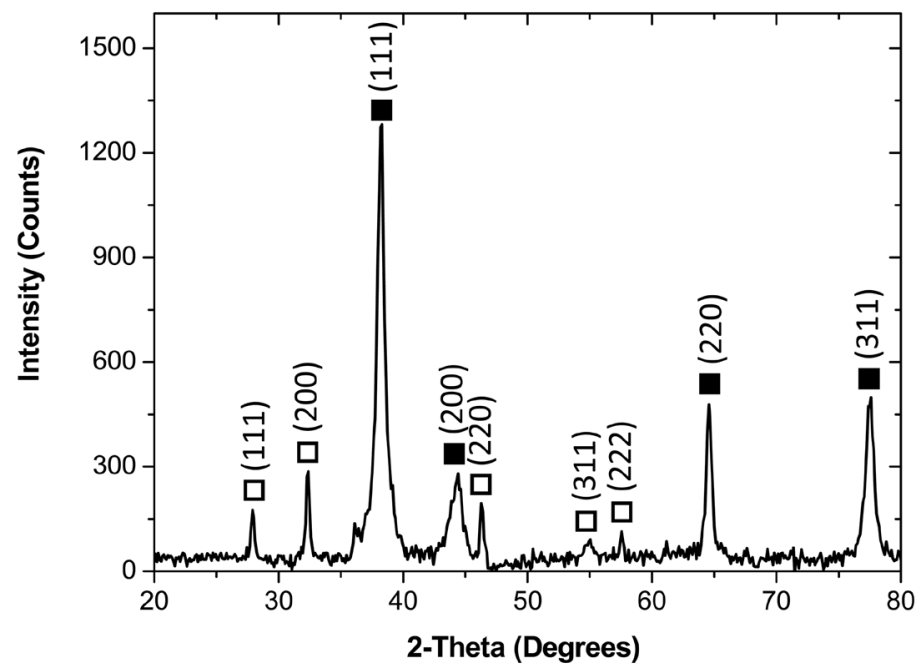

Figure 4. PXRD pattern of silver nanoparticles synthesized using Stachytarpheta cayennensis leaf extract, - represent Ag nanocrystallites and ${ }^{\circ}$ represent $\mathrm{AgCl}$ nanocrystallites. 
A Fullprof Rietveld refinement is made under Match software (Figure 5). The plot $\beta \cos \theta$ (in radians) vs. $\sin \theta$ comparison to Equation (3) (a straight-line $y=$ $m x+c(m=$ slope; $c=$ intercept $))$ allows the extraction of the strain component $4 \mathcal{E}$ from the slope (Figure 6) [21]. A separation of crystallographic planes of both type of particles $(\mathrm{Ag}$ and $\mathrm{AgCl})$ and subsequent plotting allow to calculate the parameters of Equation (3).

\subsection{SEM and EDX Morphological Studies}

Scanning electron microscopy is one of the powerful tools to identify the morphology of the synthesized nanoparticles. Figure 7 shows an SEM image of the green synthesized silver nanoparticles obtained after $24 \mathrm{~h}$ of incubation using 1 $\mathrm{mmol} / \mathrm{L}$ silver nitrate solution. The energy dispersive $\mathrm{X}$-ray analysis (EDX) is shown in Figure 8. EDX qualitative spectrum shows a strong silver peak (3 kev) along with chloride, oxygen, carbon as main elements.

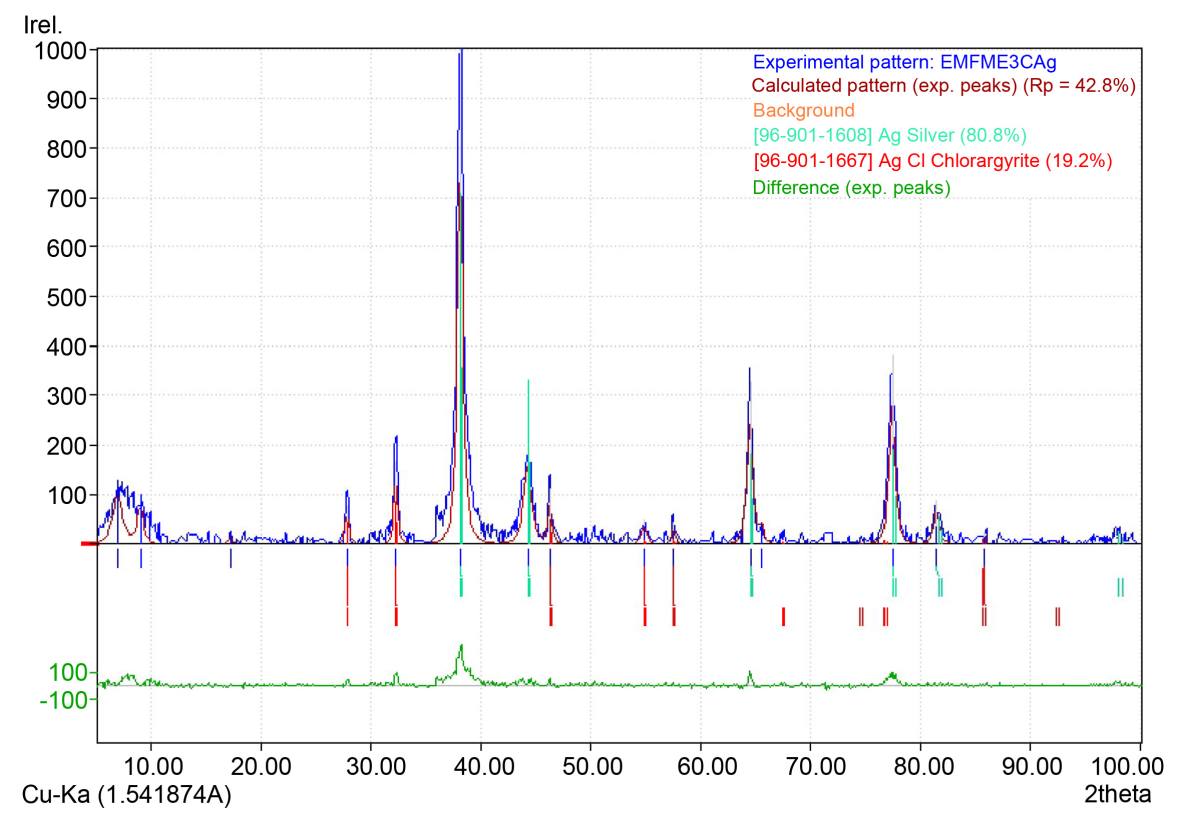

Figure 5. Rietveld refinement XRD pattern of silver nanoparticles synthesized using Stachytarpheta cayennensis leaf extract.
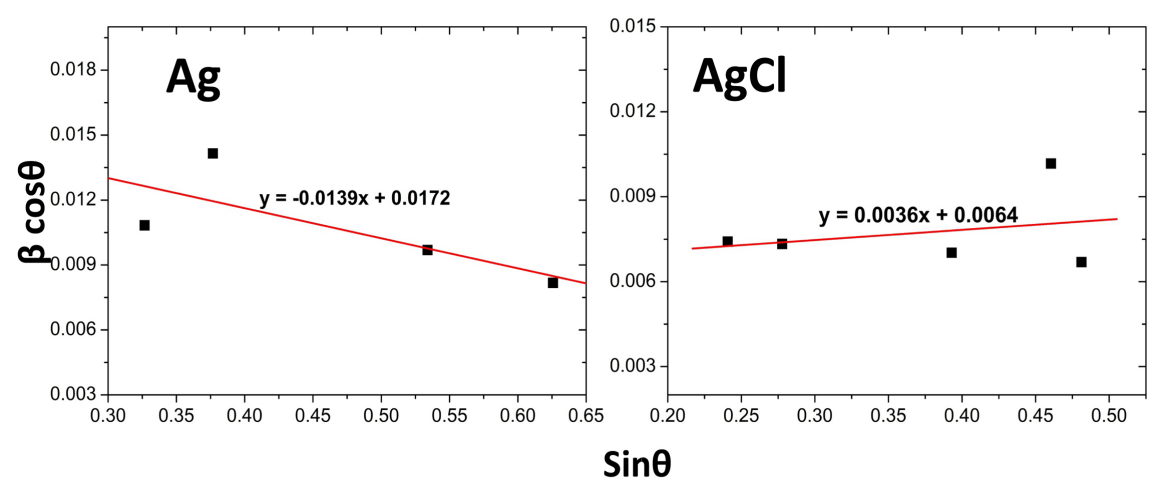

Figure 6. Williamson Hall Plot for silver and silver chloride nanoparticles. 


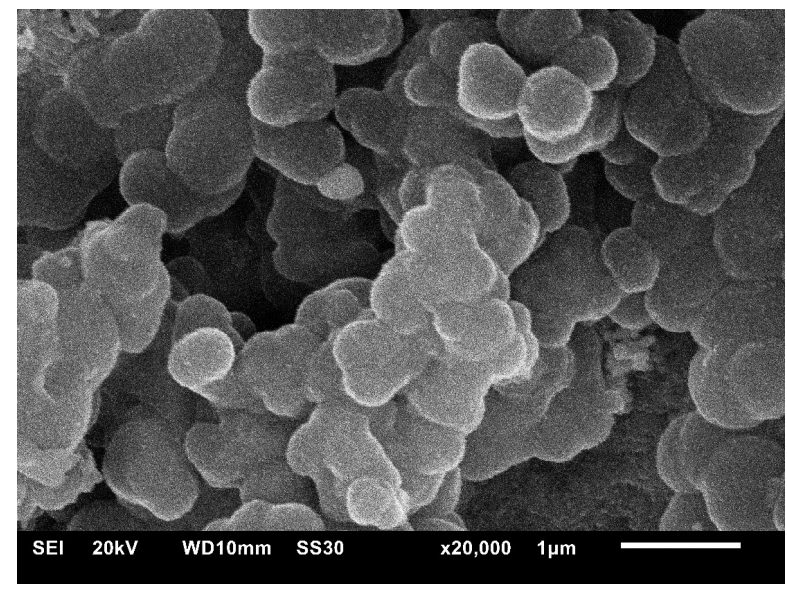

Figure 7. SEM image of Ag-Stachytarpheta cayennensisparticles, note spherical aggregates with smaller particles at the surface of larger ones.

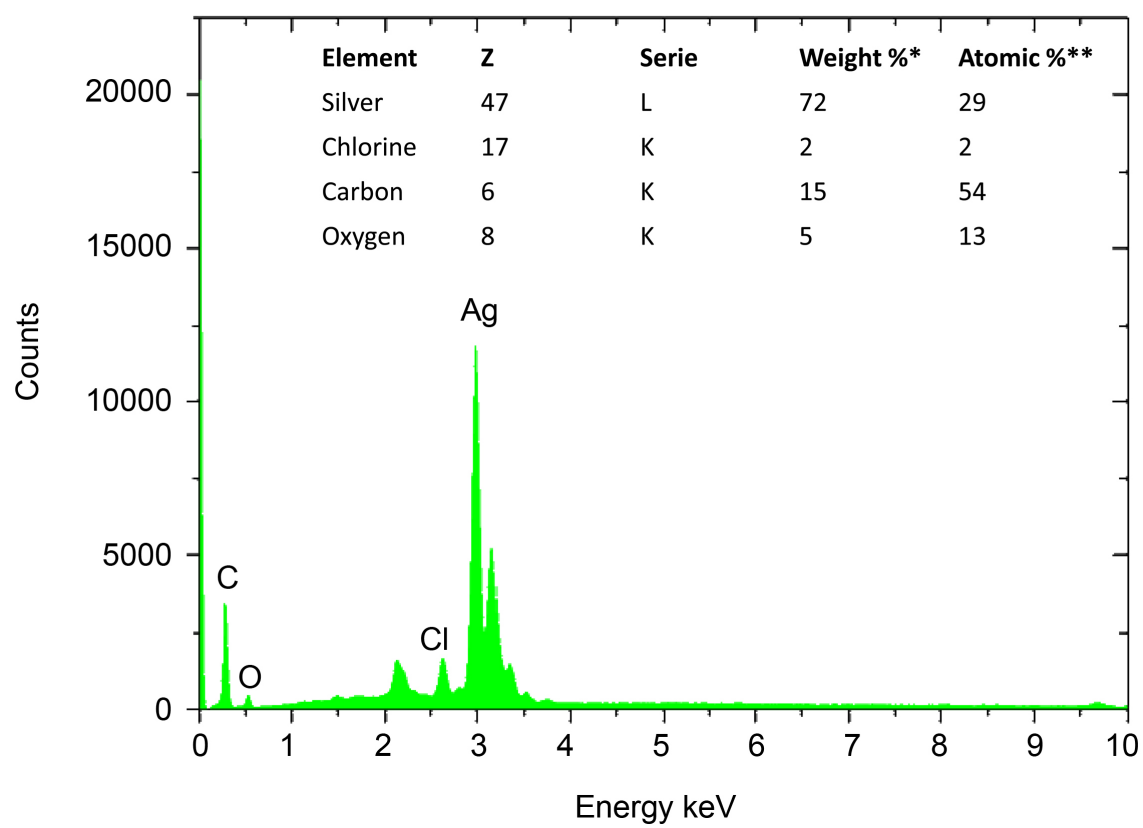

Figure 8. EDX spectrum and element mapping of Ag-Stachytarpheta cayennensis. Only main elements are represented with ${ }^{\star}(94 \%)$ and ${ }^{\star *}(98 \%)$. Other elements are Aluminium and Gold.

\subsection{Formation Mechanism of Silver Nanoparticles}

The formation mechanism is schematized in Figure 9. It involves a simultaneous formation of pure silver nanoparticles and at the same time silver chloride nanocrystallites.

\subsection{IR Spectroscopy}

Infrared spectroscopy appears as one of the key methods to study the nanoparticles-organic molecules interface. The identification of the possible functional groups involved in the reduction and the stabilization of Ag nanoparticles, can 
be extracted from the IR spectrum in Figure 10. The major frequencies of the FTIR spectra are resumed in Table 1 . The broad band peak observed at 3435 $\mathrm{cm}^{-1}$ could is assigned to stretching and deformation vibrations of $-\mathrm{NH}$ or $-\mathrm{OH}$ groups. The band situated near $2922 \mathrm{~cm}^{-1}$ can be attributed to $\mathrm{C}-\mathrm{H}$ stretching vibrations. The appearance of a band at about $2353 \mathrm{~cm}^{-1}$ is assigned to $\mathrm{C}=\mathrm{O}$ vibrations of carboxylic acids, aldehydes and ketones. The peak at $1622 \mathrm{~cm}^{-1}$ designs the stretching vibration of an amide bond. The band found at $1385 \mathrm{~cm}^{-1}$ can be assigned to characteristic bending of a $-\mathrm{C}-\mathrm{H}$ group. Bands around $1000 \mathrm{~cm}^{-1}$

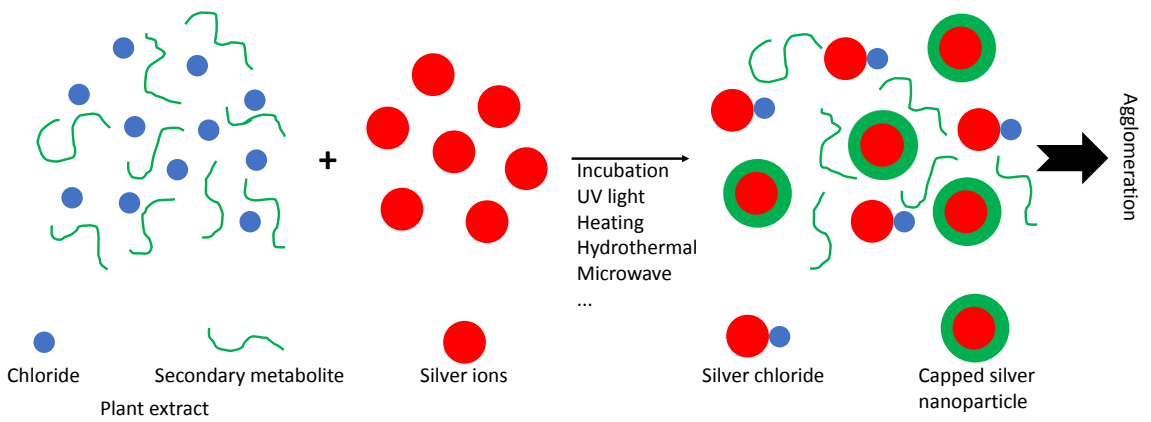

Figure 9. Synthesis mechanism of formation of silver and silver chloride nanoparticles. Counter ions have been removed for clarity and only the step before agglomeration is shown.

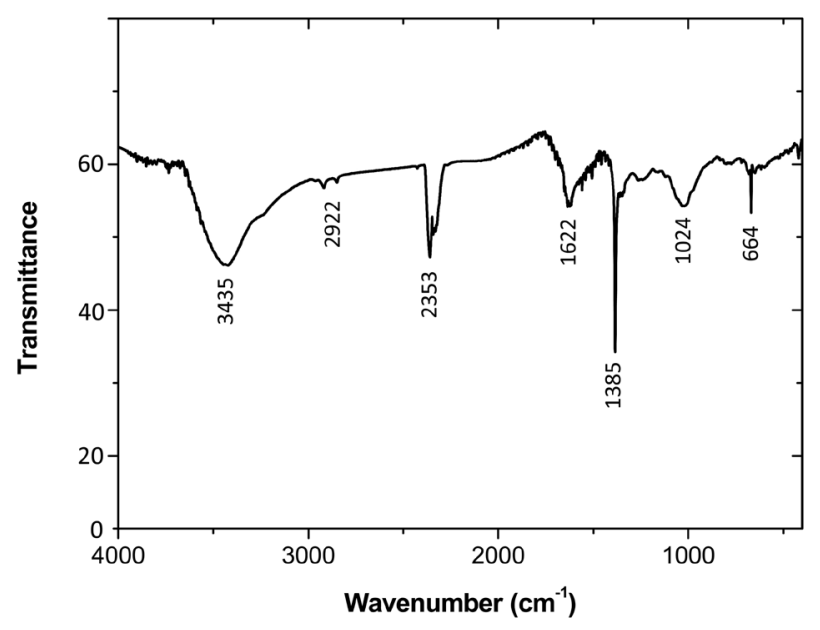

Figure 10. IR spectrum of Ag-Stachytarpheta cayennensis.

Table 1. FTIR data of Stachytarpheta cayennensis mediated silver nanoparticles.

\begin{tabular}{cc}
\hline Main functional groups & Ag-Stachytarpheta cayennensis \\
\hline O-H Stretching & 3435 \\
C-H Stretching & 2922 \\
N-H Stretching & 2353 \\
Amide Stretching & 1622 \\
-C-H Group bending & 1385 \\
Ring stretching, C-H in plane bending & 1024 \\
\hline
\end{tabular}


generally arise from ring stretching or $\mathrm{C}-\mathrm{H}$ groups in plane bending [22]. Bands lower than $1000 \mathrm{~cm}^{-1}$ are generally attributed to inter-atomic absorption vibrations of metals in fingerprint region.

\subsection{Antioxidant Activity}

The silver nanoparticles percentage inhibition of superoxide radical increases with the quantity of sample (Figure 11). The maximum inhibition of superoxide radical scavenging activity is $46 \%$ for Ag-Stachytarpheta cayennensis at the concentration of $50 \mu \mathrm{g} / \mathrm{mL}$.

The maximum phosphomolybdenum production was $68 \%$ for Ag-Stachytarpheta cayennensis at the concentration of $50 \mu \mathrm{g} / \mathrm{mL}$ (Figure 12).

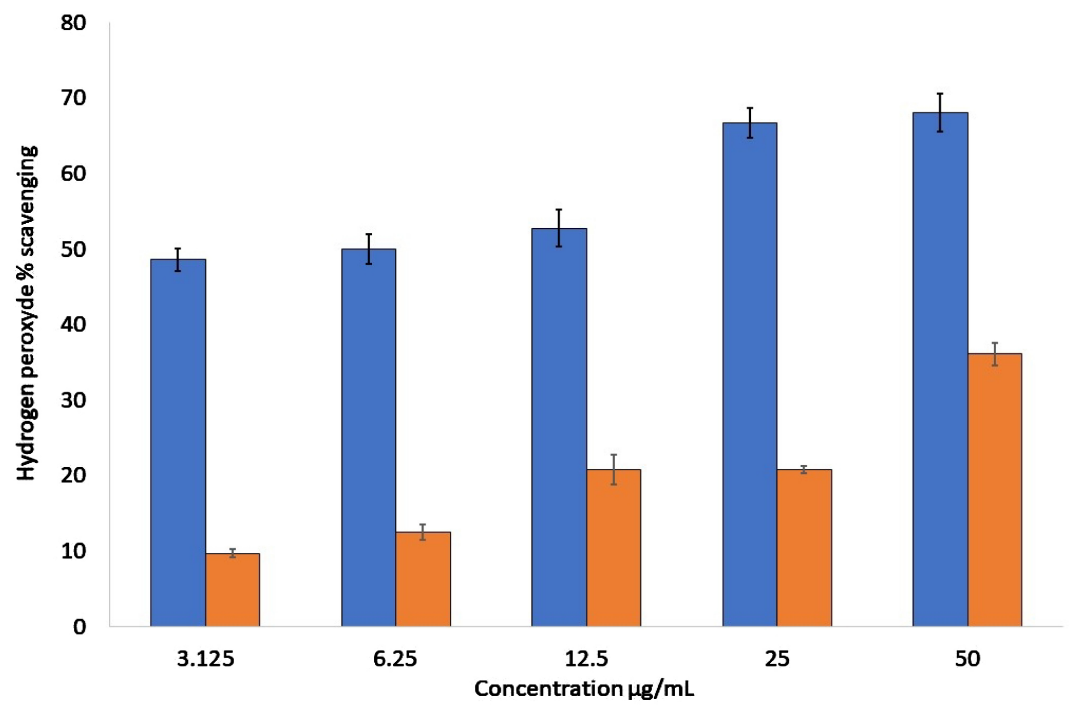

Figure 11. Antioxidant activity, hydrogen peroxide assay. Blue: Ag-Stachytarpheta cayennensis, orange: Ascorbic acid. Error bars are standard deviation.

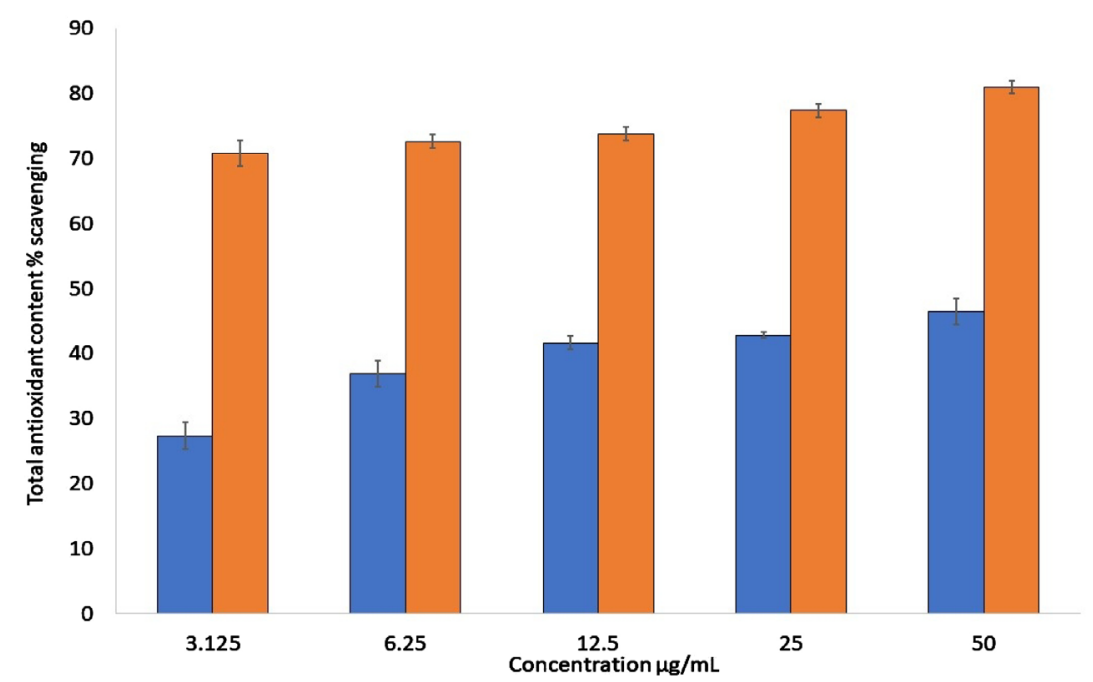

Figure 12. Antioxidant activity, phosphomolybdate assay. Blue: Ag-Stachytarpheta cayennensis, orange: Ascorbic acid. Error bars are standard deviation. 
The assay involves an electron transfer (ET) mechanism [23] and is dose-dependent (Figure 10). Values with $\mathrm{p}<0.05$ were considered as significant.

\subsection{Anti-Inflammatory Activity}

The nanoparticles on this report exhibit moderate inhibition of egg albumin denaturation by opposing to self-aggregation of proteins (Figure 13). The effect was compared to ibuprofen. The calculated anti-inflammatory action was found to be $30 \%$ for Ag-Stachytarpheta cayennensis at $50 \mu \mathrm{g} / \mathrm{mL}$.

\section{Discussion}

A visual observation gives first evidence of silver nanoparticles formation. The solution colour change within seconds to yellowish brown and deep brown due to formation of plasmons at the colloid surface. After $48 \mathrm{~h}$ of reaction, precipitation occurs indicating that the plant secondary metabolites are not able to stabilize the nanoparticles in solution by disrupting the electrostatic attractions and or the deficiency of molecules of leaf extract to act as capping agents. Thus, aggregation is not reduced by decreasing the concentration of silver salt used for the synthesis. For nanocrystals, the enhanced overlap of the electron and the hole wavefunctions in the spatially confined structure increases the excitonic binding energy, thereby making observation of the excitonic peak possible, even at room temperature. The UV absorption spectrum can also provide a qualitative indication of the size distribution. For example, sharp excitonic peak in the absorption spectra in the case of small nanocrystals (see Figure 3 ) is indeed indicative of the narrow size distribution of the nanocrystals in the sample [24]. A signal is recorded in the ultraviolet visible spectra due to surface plasmon resonance of Ag-nanoparticles [25].

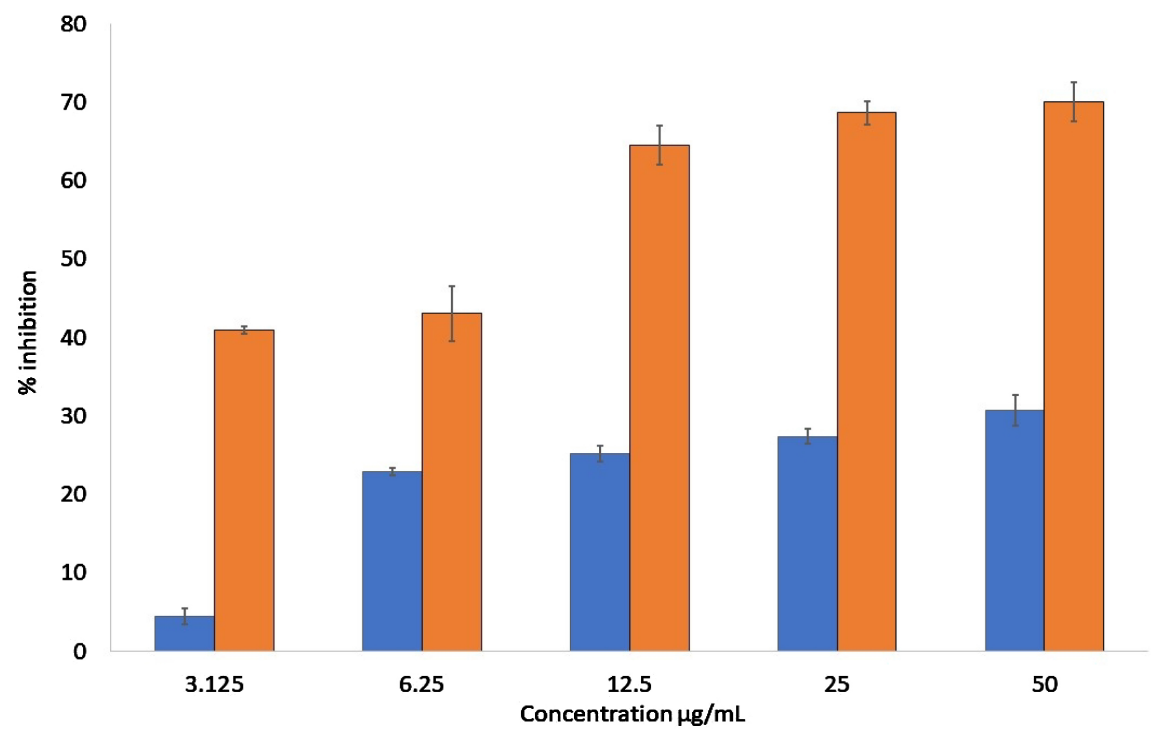

Figure 13. Albumin denaturation assay. Blue: Ag-Stachytarpheta cayennensis, orange: Ibuprofen. Error bars are standard deviation. 
Powder diffraction is the key method for phase and nature identification and is widely used in nanoparticles characterisation. Match identification software confirm presence of $\mathrm{Ag}$ and $\mathrm{AgCl}$ nanomixture. A similar observation was made using leaf extracts of Corchorus olitorus and Ipomea batatas or flowers extract of Albizia julibrissin [11] [26]. No other characteristic peaks were found in the $\mathrm{XRD}$ spectra, indicating the high purity of the prepared $\mathrm{Ag}$ and $\mathrm{AgCl}$ nanoparticles. To calculate the average crystalline particle size of the synthesized nanoparticles, the most intense peaks of $\mathrm{Ag}$ and $\mathrm{AgCl}$ were preferred [27]. Therefore, we've selected the (111) and (200) lattice planes of $\mathrm{Ag}$ and $\mathrm{AgCl}$ respectively. The calculated average crystalline particle sizes were found to be $13 \mathrm{~nm}$ and 20 $\mathrm{nm}$ for $\mathrm{Ag}$ and $\mathrm{AgCl}$ respectively. The intense and narrow diffraction peaks revealed the crystalline nature of the synthesized nanoparticles [28]. Therefore, in the nanoparticle system $\mathrm{AgCl}$ is less crystalline than Ag.

The Williamson Hall plot is in this work for the first time presented for a mixture of $\mathrm{Ag}$ and $\mathrm{AgCl}$ nanoparticles. The calculated average crystalline particle sizes were found to be $7 \mathrm{~nm}$ and $19 \mathrm{~nm}$ for $\mathrm{Ag}$ and $\mathrm{AgCl}$, respectively. The differences with the Scherrer equation size results may be due to the contribution of strain and instrument broadening. The Ag-Stachytarpheta cayennensis strains of -0.0034 and 0.0009 for $\mathrm{Ag}$ and $\mathrm{AgCl}$ values are extracted from the straight lines. The negative slope $4 \mathcal{E}$ of Figure 4 indicates that micro-strains cannot be a dominant source of broadening or proves that the strain is compressive while positive value indicates an expansion of the strain [29]. The low values indicate the occurrence of lattice relaxation within nanocrystallites [19]. The nonlinearity between $\beta \cos \theta$ and $\sin \theta$ can be due to low crystallized powder samples [29].

Microscopy investigation shows large sized spherical grains that may have grown from the coalescences of small particles. The presence of carbon and oxygen is a proof of the presence of capping secondary metabolites whereas chlorine comes from silver chloride nanocrystallites. Evidence of the presence of chlorine in the nanoparticles sample comes from PXRD and EDX elemental mapping analysis. The properties of the nanoparticles are affected by the synthesis process. It is then possible to tailor the properties of the obtained material to particular applications. A possible reaction scheme described by Awwad and coworkers (2015) involves the transfer of chlorine from organochlorine secondary metabolites in plants to generate $\mathrm{Ag}-\mathrm{AgCl}$ nanoparticles [26]. In the reaction mechanism in this work described, there is a competition in the growing of silver and silver chloride nanoentities. Silver chloride is formed by the competitive reaction of free chloride. This mechanism considers that chlorine is an essential micronutrient for higher plants and is present mainly as $\mathrm{Cl}^{-}$counter ions, although plants do contain compounds with covalently bound $\mathrm{Cl}$. Chloride is a major osmotically active solute in the vacuole and is involved in both turgorand osmoregulation [30]. Free silver ions react readily with chloride to give insoluble silver chloride which poses environmental issues. It is unclear if the fast agglomerating structure is a core shell, simple mixture or a cluster. This ag- 
glomeration is based on the principles of the Ostwald ripening as a thermodynamically driven spontaneous process because larger particles are more energetically favoured than smaller ones [31] [32]. This fact originates from coordinatively unsaturated surface atoms which are energetically less stable than well-ordered and fully coordinated atoms in the bulk [33]. The assembly contains silver nanoparticles with reducing and capping metabolites. FTIR spectral studies suggest that the amide and hydroxyl groups found in proteins and polyphenols have a stronger affinity to bind with metal and facilitate the formation of a coat over the nanoparticles.

The development of nanoparticles used as therapeutic agents has introduced new opportunities for the improvement of medical treatment [34]. Traditional therapy often fails to treat inflammatory diseases due to lack in the bioavailability of the drug, harmful side effects and development of drug resistance [35]. Most of the semiconductor and metallic nanoparticles have immense potential for cancer diagnosis and therapy on account of their surface plasmon resonance enhanced light scattering and absorption [36]. Antioxidants can play a protective role in a number of diseases such as cardiovascular and neurodegenerative diseases in which oxidative stress and free radicals are the major contributors [37]. Therefore, silver nanoparticles perform well as cancer therapeutics because they can disrupt the mitochondrial respiratory chain, which induces the generation of reactive oxygen species and ATP synthesis, which can induce DNA damage [38] [39]. The superoxide anion radical is recognized to be very injurious to cellular components as a herald of more reactive oxygen species, contributing to tissue damage and various diseases [40]. The literature described biosynthesized silver nanoparticles showed potent scavenging activities of $77 \%$ 99.8\% against $\mathrm{H}_{2} \mathrm{O}_{2}$ [14] [41]. A moderate maximum inhibition of superoxide radical scavenging activity of $46 \%$ at $50 \mu \mathrm{g} / \mathrm{mL}$ has been obtained. The molybdenum assay is based on the reduction of $\mathrm{Mo}(\mathrm{VI})$ to $\mathrm{Mo}(\mathrm{V})$ by the nanoparticles in the presence of sodium phosphate in acidic medium and the subsequent formation of phosphomolybdenum. The maximum phosphomolybdenum production was $68 \%$ for Ag-Stachytarpheta cayennensis at the concentration of $50 \mu \mathrm{g} / \mathrm{mL}$. Silver nanoparticles are suggested to act as electron donors, reacting with free radicals to convert them to more stable products, which can terminate radical chain reaction. Moreover, the reducing power of Ag nanoparticles correlated well with the radical scavenging activity [42].

Reaction of albumin with nanoparticles results in a physical adsorption of protein on the nanoparticles surface. A complex is formed which is usually isolated by centrifugation. In that reaction albumin is the reducing agent and a stabilizer [43]. The study of the impact of nanoparticles on protein aggregation is an area of considerable research considering their use as anti-inflammatory or anti-neurodegeneratives agents. In related diseases, solubles proteins and peptides are converted into highly organized fibrillar aggregates. The accumulation of abnormal protein and peptide aggregates exerts toxicity by disrupting intra- 
cellular transport, overwhelming protein degradation pathways and/or disturbing vital cell functions [3]. Thermal denaturation of albumin leads to the exposure of hydrophobic residues, which increases hydrophobic attraction that overcomes electrostatic repulsion and triggers the aggregation of amorphous aggregates [3]. Protein denaturation is a process in which protein tertiary or secondary structure is disturbed by the application of external stress. It is a well-known cause of inflammation [4]. 30\% antiinfmammation action for Ag-Stachytarpheta cayennensis was found at $50 \mu \mathrm{g} / \mathrm{mL}$. These biogenerated nanoparticles may find application in specific and systemic inflammation as well as degeneration in in-vitro models and in-vivo preclinical models or in drug synergy.

\section{Conclusion}

We have described a simple green method for silver nanoparticle synthesis using the reducing properties of Stachytarpheta cayennensis leaf aqueous extract. The extract of Stachytarpheta cayennensis leaves in contact with silver ions is capable of producing silver nanoparticles within $5 \mathrm{~min}$. The extract acts as reductant and stabilizer and the nanoparticles can be prepared easily, rapidly and in a cost-effectively manner. Powder X-ray diffraction studies with Scherrer equation and Williamson-Hall plot confirm the pure nature of the crystallites composed with $\mathrm{Ag}$ and $\mathrm{AgCl}$. Williamson-Hall negative slopes have been obtained for silver while positive slopes have been obtained for silver chloride. A mechanism of formation consisting of simultaneous and competitive formation before agglomeration of both species is presented. The synthesized silver nanoparticles exhibit antiinflammation and moderate proregenerative action.

\section{Acknowledgements}

The authors thank the Multidisciplinary Laboratory of the Faculty of Medicine and Pharmaceutical Sciences, Department of Pharmaceutical Sciences for technical support. Support of Word University Service under APA 2668 for providing part equipment used is appreciated. EMF thanks the German Academic Exchange Service DAAD for a generous Professor Fellowship (grant No. 768048).

\section{Conflicts of Interest}

The authors declare no conflicts of interest regarding the publication of this paper.

\section{References}

[1] Calcott, P.D.J., Nash, K.J., Canham, L.T., Kane, M.J. and Brumhead, D. (1993) Identification of Radiative Transitions in Highly Porous Silicon. Journal of Physics Condensed Matter, 5, L91. https://doi.org/10.1088/0953-8984/5/7/003

[2] Beriso, A. and Ghoshal, S.K. (2018) Study of Dependence of Optical Parameters on the Size of Nanoporous Silicon Quantum Dot through Energy Gap. Advances in 
Physics Theories and Applications, 72, 8-19.

[3] Shanker, U., Jassal, V., Rani, M. and Kaith, B.S. (2016) Towards Green Synthesis of Nanoparticles: From Bio-Assisted Sources to Benign Solvents. A Review. International Journal of Environmental and Analytical Chemistry, 96, 801-835.

[4] Pandiarajan, J., Balaji, S., Mahendran, S., Ponmanickam, P. and Krishnan, M. (1996) Synthesis and Toxicity of Silver Nanoparticles. In: Ranjan, S., et al., Eds., Nanosciences in Food and Agriculture 3, Springer International Publishing, Switzerland, 73-98.

[5] Silva, L.P., Reis, I.G. and Bonatto, C.C. (2015) Green Synthesis of Metal Nanoparticles by Plants: Current Trends and Challenges. In: Basiuk, V. and Basiuk, E., Eds., Green Processes for Nanotechnology, Springer, Cham, 259-275.

https://doi.org/10.1007/978-3-319-15461-9_9

[6] Metz, K.M., Sanders, S.E., Pender, J.P., Dix, M.R., Hinds, D.T., Quinn, S.J., Ward, A.D., Duffy, P., Cullen, R.J. and Colavita, P.E. (2015) Green Synthesis of Metal Nanoparticles via Natural Extracts: The Biogenic Nanoparticle Corona and Its Effects on Reactivity. ACS Sustainable Chemistry and Engineering, 3, 1610-1617.

https://doi.org/10.1021/acssuschemeng.5b00304

[7] Parashar, V., Parashar, R., Sharma, B. and Pandey, A.C. (2009) Parthenium Leaf Extract Mediated Synthesis of Silver Nanoparticles: A Novel Approach towards Weed Utilization. Digest Journal of Nanomaterials and Biostructures, 4, 45-50.

[8] Roy, N. and Barik, A. (2010) Green Synthesis of Silver Nanoparticles Using Unexploited Weed Resources. International Journal of Nanotechnology and Application, 4, 95-101.

[9] Schapoval, E.E.S., De Vargas, W.M.R., Chaves, C.G., Bridi, R., Zuanazzi, J.A. and Henriques, A.T. (1998) Antiinflammatory and Antinociceptive Activities of Extracts and Isolated Compounds from Stachytarpheta cayennensis. Journal of Ethnopharmacology, 60, 53-59. https://doi.org/10.1016/S0378-8741(97)00136-0

[10] Adebajo, A.C., Olawode, O.R., Adesanya, S.A., Begrow, F., Elkhawad, A., Akanmum, R., Edrada, M., AProksh, P. and Scmidt, T.J. (2007) Hypoglycemic Constituent of Stachytarpheta cayennensis Leaf. Planta Medica, 73, 241-250.

https://doi.org/10.1055/s-2007-967125

[11] Okoye, T.C., Akah, P.A., Okoli, C.O., Ezike, A.C. and Mbaoji, F.N. (2010) Antimicrobial and Antispasmodic Activity of Leaf Extract and Fractions of Stachytarpheta cayennensis. Asian Pacific Journal of Tropical Medicine, 3, 189-192. https://doi.org/10.1016/S1995-7645(10)60006-5

[12] Meva, F. E., Segnou, M.L., Ebongue, C.O., Ntoumba, A.A., Steve, D.Y., Malolo, F. E.A., Ngah, L., Massai, H. and Mpondo, E.M. (2016) Unexplored Vegetal for the Green Synthesis of Silver Nanoparticles: A Preliminary Study with Corchorus olitorus Linn and Ipomoea batas (L.) Lam. African Journal of Biotechnology, 15, 341-349. https://doi.org/10.5897/AJB2015.14962

[13] Putz, H. and Brandenburg, K.G. Match!-Phase Identification from Powder Diffraction. Crystal Impact, Bonn, Germany. http://www.crystalimpact.com/match

[14] Rodríguez-Carvajal, J. (1990) Fullprof: A Program for Rietveld Refinement and Pattern Matching Analysis. Satellite Meeting on Powder Diffraction of the $X V$ Congress of the IUCr, Toulouse, France, 16-19 July 1990, 127.

[15] Bhakya, S., Muthukrishnan, S., Sukumaran, M. and Muthukumar, M. (2016) Biogenic Synthesis of Silver Nanoparticles and Their Antioxidant and Antibacterial Activity. Applied Nanoscience, 6, 755-766. https://doi.org/10.1007/s13204-015-0473-z

[16] Prieto, P., Pineda, M. and Aguilar, M. (1999) Spectrophotometric Quantitation of 
Antioxidant Capacity through the Formation of a Phosphomolybdenum Complex Specific Application to the Determination of Vitamin E. Analytical Biochemistry, 269, 337-341. https://doi.org/10.1006/abio.1999.4019

[17] Ullah, H.M.A., Zaman, S., Juhara, F., Akter, L., Tareq, S.M., Masum, E.H. and Bhattacharjee, R. (2014) Evaluation of Antinociceptive, In-Vivo and In-Vitro Anti-Inflammatory Activity of Ethanolic Extract of Curcuma zedoaria Rhizome. Complementary and Alternative Medicine, 14, 346.

https://doi.org/10.1186/1472-6882-14-346

[18] Ebanda, B.K.P., Meva, E.F., Kotsedi, L., Nguemfo, E.L., Zangueu, C.B., Ntoumba, A.A., Mohamed, H.E.A., Dongmo, A.B. and Maaza, M. (2018) Eco-Friendly Synthesis, Characterization, in Vitro and in Vivo Anti-Inflammatory Activity of Silver Nanoparticle-Mediated Selaginella myosurus Aqueous Extract. International Journal of Nanomedicine, 13, 8537-8548. https://doi.org/10.2147/IJN.S174530

[19] Rani, R., Sharma, S., Quaglio, M., Rai, R., Bianco, S., Pugliese, D. and Pirri, C.F. (2017) A Novel Low Temperature Synthesis of KNN Nanoparticles by Facile Wet Chemical Method. Materials Sciences and Applications, 8, 247-257. https://doi.org/10.4236/msa.2017.83017

[20] Khan, M.A.M., Kumar, S., Ahamed, M., Alrokayan, S.A. and AlSalhi, M.S. (2011) Structural and Thermal Studies of Silver Nanoparticles and Electrical Transport Study of Their Thin Films. Nanoscale Research Letters, 6, 434. https://doi.org/10.1186/1556-276X-6-434

[21] Rani, R. and Sharma, S. (2016) Preparation and Characterization of $\mathrm{SnO}_{2}$ Nanofibers via Electrospinning. Advances in Nanoparticles, 5, 53-59. https://doi.org/10.4236/anp.2016.51006

[22] Theivasanthi, T. and Alagar, M. (2012) Electrolytic Synthesis and Characterizations of Silver Nanopowder. Nano Biomedicine and Engineering, 4, 58-65. https://doi.org/10.5101/nbe.v4i2.p58-65

[23] Ahmed, D., Khan, M.M. and Saeed, R. (2015) Comparative Analysis of Phenolics, Flavonoids, and Antioxidant and Antibacterial Potential of Methanolic, Hexanic and Aqueous Extracts from Adiantum caudatum Leaves. Antioxidants, 4, 394-409. https://doi.org/10.3390/antiox4020394

[24] Rao, C.N.R. and Muller, A. (2004) The Chemistry of Nanomaterials: Synthesis, Properties and Applications. Wiley-VCH Verlag GmbH \& Co. KGaA, Weinheim. https://doi.org/10.1002/352760247X

[25] Mulvaney, P. (1996) Surface Plasmon Spectroscopy of Nanosized Metal Particles. Langmuir, 12, 788-800.

[26] Awwad, A.M., Salem, N.M., Ibrahim, Q.M. and Abdeen, A.O. (2015) Phytochemical Fabrication and Characterization of Silver/Silver Chloride Nanoparticles Using Albiziajulibrissin Flowers Extract. Advanced Materials Letters, 6, 726-730. https://doi.org/10.5185/amlett.2015.5816

[27] Meva, F.E., Ebongue, C.O., Fannang, V.S., Segnou, M.L., Ntoumba, A.A., Kedi, P. B.E., Loudang, R.E.N., Wanlao, A.Y., Mang, R.E. and Mpondo, M.E.A. (2017) Natural Substances for the Synthesis of Silver Nanoparticles Against Escherichia coli: The Case of Megaphrynium macrostachyum (Marantaceae), Corchorus olitorus (Tiliaceae), Ricinodendron heudelotii (Euphorbiaceae), Gnetum bucholzianum (Gnetaceae), and Ipomoea batatas (Convolvulaceae). Journal of Nanomaterials, 2017, Article ID: 6834726. https://doi.org/10.1155/2017/6834726

[28] Wang, P., Huang, B., Lou, Z., Zhang, X., Qin, X., Dai, Y., Zheng, Z. and Wang, X. (2010) Synthesis of Highly Efficient Ag@AgCl Plasmonic Photocatalyst with Vari- 
ous Structures. Chemistry-A European Journal, 16, 538-544. https://doi.org/10.1002/chem.200901954

[29] Inagaki, M., Nonaka, R., Tryba, B. and Morawski, A.W. (2006) Dependence of Photocatalytic Activity of Anatase Powders on Their Crystallinity. Chemosphere, 64, 437-445. https://doi.org/10.1016/j.chemosphere.2005.11.052

[30] White, P.J. and Broadley, M.R. (2001) Chloride in Soils and Its Uptake and Movement within the Plant: A Review. Annals of Botany, 88, 967-988. https://doi.org/10.1006/anbo.2001.1540

[31] Ostwald, W. (1901) Blocking of Ostwald Ripening Allowing Long-Term Stabilization. Zeitschrift für Physikalische Chemie, 37, 385.

[32] Ostwald, W. (1986) Lehrbuch der Allgemeinen Chemie. Zeitschrift für Anorganische und Allgemeine Chemie, 15, 540-614.

[33] Janiak, C. (2013) Ionic Liquids for the Synthesis and Stabilization of Metal Nanoparticles. Zeitschrift für Naturforschung, 68, c1056-c1089.

[34] Thilagavathi, T., Kathiravan, G. and Srinivasan, K. (2016) Antioxidant Activity and Synthesis of Silver Nanoparticles Using the Leaf Extract of Limona acidissima. International Journal of Pharmacy and Biological Sciences B, 7, 201-205.

[35] Banerjee, S.K., Jagannath, C., Hunter, R.L. and Dasgupta, A. (2000) Bioavailability of Tobramycin after Oral Delivery in FVB Mice Using CRL-1605 Copolymer, an Inhibitor of P-Glycoprotein. Life Sciences, 67, 2011-2016. https://doi.org/10.1016/S0024-3205(00)00786-4

[36] Khan, I., Saeed, K. and Khan, I. (2017) Nanoparticles: Properties, Applications and Toxicities. Arabian Journal of Chemistry, in press. https://doi.org/10.1016/j.arabjc.2017.05.011

[37] Rajan Rushender, C., Eerike, M., Madhusudhanan, N. and Konda, V.G.R. (2012) In Vitro Antioxidant and Free Radical Scavenging Activity of Nymphaca pubescens. Journal of Pharma Research, 5, 3804-3806.

[38] AshaRani, P.V., Mun, G.L.K., Hande, M.P. and Valiyaveettil, S. (2009) Cytotoxicity and Genotoxicity of Silver Nanoparticles in Human Cells. ACS Nano, 3, 279-290. https://doi.org/10.1021/nn800596w

[39] Morones, J.R., Elechiguerra, L.J., Camacho, A., Holt, K., Kouri, B.J. and Ramirez, T.J. (2005) The Bacterial Effect of Silver Nanoparticles. Nanotechnology, 16, 2346-2353. https://doi.org/10.1088/0957-4484/16/10/059

[40] Nordberg, J. and Arnér, E.S.J. (2001) Reactive Oxygen Species, Antioxidants, and the Mammalian Thioredoxin System. Free Radical Biology and Medicine, 31, 1287-1312. https://doi.org/10.1016/S0891-5849(01)00724-9

[41] Mata, R., Nakkala, J.R. and Sadras, S.R. (2015) Catalytic and Biological Activities of Green Silver Nanoparticles Synthesized from Plumeria alba (Frangipani) Flower Extract. Materials Science and Engineering. C, 51, 216-225. https://doi.org/10.1016/j.msec.2015.02.053

[42] Khan, A.U., Weil, Y., Khan, Z.U.H., Tahir, K., Khan, S.U., Ahmad, A., Khan, F.U., Cheng, L. and Yuan, Q. (2015) Electrochemical and Antioxidant Properties of Biogenic Silver Nanoparticles. International Journal of Electrochemical Science, 10, 7905-7916.

[43] Mariam, J., Sivakami, S. and Dongre, P.M. (2015) Albumin Corona on Nanoparticles-A Strategic Approach in Drug Delivery. Drug Delivery, 23, 2668-2376. https://doi.org/10.3109/10717544.2015.1048488 